\title{
LA COMPARACIÓN COMO RECURSO CRÍTICO EN “EL ESPÍRITU DE MI TIERRA"
}

\author{
José Ángel Vargas Vargas
}

\begin{abstract}
RESUMEN
En este artículo se analiza el texto "El espíritu de mi tierra" (1937), con el fin de determinar en qué consiste la visión crítica que Yolanda Oreamuno construye en torno al campesino. Se estudian las formas de comparación que presenta el texto y se enfatiza en la selección de insecto denominado chicharra como el principal núcleo generador de la semiosis. El análisis permite, además, observar la elaboración discursiva de una imagen del campesino contradictoria con la que había predominado en la literatura costarricense de otros autores de las tres primeras décadas del siglo veinte, principalmente por una fractura ideológica que afecta el imaginario colectivo nacional.

Palabras clave: Yolanda Oreamuno, literatura costarricense, campesino, chicharra, comparación.
\end{abstract}

\begin{abstract}
This article analyzes the text "The Spirit of My Land" with the intent of determining of what the critical vision consists that Yolanda Oreamuno constructs around farmers. Forms of comparison are studied as presented by the text, and emphasizes the selection of the insect called the cicada as the principle generating nucleus of semiosis. The analysis allows as well to observe the discursive elaboration of a contradictory image of the farmer than what has predominated in the works of other authors in Costa Rican literature in the last three decades of the twentieth century, principally, through a ideological fracture which affects the collective national imagery.
\end{abstract}

Key words: Yolando Oreamuno, Costa Rican literature, farmers, cicada, comparison.

José Ángel Vargas Vargas. Doctor en Literatura, Profesor Catedrático, Universidad de Costa Rica. San Pedro, San José, Costa Rica.

Correo electrónico: vyvosa@racsa.co.cr

Recepción: 17- 9- 2008

Aceptación: 23- 10- 2008 


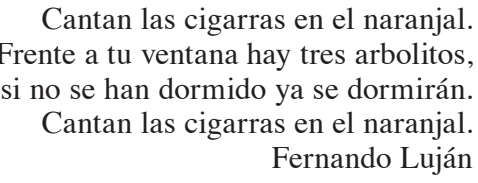

\section{Introducción}

El discurso literario como un modo enunciativo de modelizar realidades históricas y culturales específicas aporta a la configuración de diversas imágenes del mundo y por lo tanto, ficcionaliza temáticas y aspectos concretos de determinadas sociedades. En el caso de la literatura costarricense, desde finales del siglo XIX, ésta se ha integrado a una serie de discursos orientados a la búsqueda y definición de una identidad nacional en la que se resaltan, valoran y apropian elementos simbólicos del imaginario colectivo, en los cuales, incluso, se enmascaran y esconden signos y situaciones muy heterogéneas. Bajo las codificaciones de himno nacional, teatro nacional y literatura nacionalista se encuentran semas que revelan relaciones de exclusión, posiciones ideológicas y posibilidades significativas que desnudan la aparente homogeneidad que engloban.

Desde el punto de vista del desarrollo histórico de la literatura costarricense, ha habido escritores que contribuyen a fortalecer el sentido de identidad presente en los discursos hegemónicos, discursos que apuntan hacia la unidad del ser costarricense. Álvaro Quesada, en su libro La formación de la narrativa nacional costarricense (1986), cuando analiza la actitud anecdótica refiere múltiples ejemplos de textos y autores en los que se privilegian y subrayan vínculos de armonía entre los peones y los patronos. Ellos han pretendido contribuir a la definición del ser nacional y, en este afán, el hombre costarricense y más precisamente, el campesino, ha sido núcleo y germen de diversas creaciones literarias, como las de Manuel González Zeledón, Ricardo Fernández Guardia, Jenaro Cardona, Joaquín García Monge, Carlos Luis Fallas, para citar algunos de los principales.

No podríamos tampoco efectuar afirmaciones absolutizantes que borren las particularidades de escritura de cada texto, pero sí marcar importantes coincidencias. Sin embargo, existen autores que asumen estos elementos de la realidad ("realemas") y les dan un tratamiento literario específico, tal es el caso en escritores de principios y mediados del siglo XX como Max Jiménez y Yolanda Oreamuno. En este trabajo se analiza el texto "El espíritu de mi tierra" de Yolanda Oreamuno, escrito en agosto de 1937 y que aparece recopilado en A lo largo del corto camino (1961); concretamente en la segunda parte denominada "Literatura dispersa". Se pretende determinar el modo como la escritora recurre a la comparación para conformar una visión crítica del ser nacional tomando como elemento primario al campesino. Se determinan las formas de comparación que presenta el texto y se enfatiza, en la escogencia del insecto denominado "chicharra", como núcleo de confluencia y contradicción con respecto a la imagen predominante del campesino elaborada por otros autores de la literatura costarricense.

\section{El texto como búsqueda}

El cuadro inicial del texto se caracteriza por presentar una retórica en la que se privilegia el tópico de la indagación y la búsqueda como elementos que permiten alcanzar una definición de lo que la autora ha denominado "espíritu de mi tierra", de manera que no 
se parte de un concepto predeterminado sino de una actitud explorativa. Los tres espacios seleccionados por los que se guiará la búsqueda, la cual se constituye en un leifmotiv, son los mares, las calles y el bosque, como puede apreciarse en el incipit:

\begin{abstract}
Estoy llena de mis propios pensamientos. Llena por dentro como una tinaja con su agua. He pensado en el viento. Tengo que pensar en un hilo recorriendo la tierra, para dar con lo que busco. Es que hoy, no sé cuándo ni en qué momento, he pensado en el espíritu de mi tierra. Lo he sentido; pero no sé dónde lo he sentido. Sé que para encontrarlo tengo que seguir el hilo del viento, que es el que viaja desde el norte hasta el sur, el que conoce los mares, el que pasea por las calles y el que se enreda en el bosque. Para encontrar eso que busco, y que siento y adivino sin saberlo, sé que tengo que seguir el hilo del viento (150).
\end{abstract}

La fuerza actancial que constituye el soporte para lograr la búsqueda es el viento, y más específicamente "el hilo" del viento, que recorre todo el territorio. Aquí el viento es asumido simbólicamente y, como tal, representa el espíritu animador (Tresidder 246). Su rasgo de invisibilidad apunta también a una condición necesaria para indagar y conocer al hombre, al individuo. No es por lo fenotextual y evidente, sino por aquello que se calla o se esconde como se puede acceder al sentido más sutil del sujeto. El texto connota, de alguna manera, una fuerza vital que posibilita el conocimiento. No obstante este sentido positivo, junto a esa búsqueda aparece la duda y la ambigüedad, porque el sujeto de enunciación afirma estar llena de sus propios pensamientos, pero no sabe dónde ha sentido "el espíritu" de su tierra.

La búsqueda esbozada en el incipit parte de una comparación implícita en donde la actitud de indagación se fundamenta en aquello que puede impactar por lo que significa y no únicamente por ser visible: "El sentido de mi tierra no hay que verlo. Hay que oírlo" (152). Para describir la tierra se recurre a una comparación. De la tierra en el norte se afirma que es reseca y ardiente, con vastos horizontes pelados. Ahí el viento se aburre. Es una tierra mugrienta y curtida en su superficie:

\begin{abstract}
Allá en el norte. La tierra se ha tendido como una colcha sobre la superficie de una cama y pareciera que no encontrando todavía esqueleto, está tirante y abierta. Hacen mañanas que son como un gran hueco rosado que sucediera a otro hueco, el aire adquiere vibraciones de infinito y el eco parece que se paseara en el ambiente. Todo está lleno de densidades calientes, la tierra rendida, sin huequecitos de sombra, sin niditos de tibieza, toda ella regada sobre ella misma, engañosa, horizontal, en verano curtida y mugrienta como esos chiquillos de la calle a quienes la suciedad ha formado un segundo aspecto de ellos mismos (150).
\end{abstract}

En el texto se insiste en que la esencia verdadera de la tierra está escondida, de ahí que se proponga una subdivisión en dos tierras, la cual implica también un modo de comparación: la visible y superficial; y la verdadera, la escondida, la que produce el alimento y el pasto. La primera constituye la falsedad, la máscara. La segunda se mantiene virgen e intacta porque no se deja manosear por el viento infiel, inútil y vagabundo; es estática e inconmovible (151) y, por lo tanto, auténtica. Esta diferencia o dualidad en cuanto a la tierra es trasladada en sentido metafórico al hombre y al campesino, que por una parte puede presentarse enmascarado en su superficialidad y por la otra, esconde su esencia. De ese modo, el texto constituye una invitación a observar y a escuchar en un marco profundo y no solamente en aquello que resulta tangible.

\title{
3. La comparación
}

Estas comparaciones que aparecen en las primeras páginas sirven de sustento a una mayor, que en realidad es dominante y permite construir una perspectiva crítica del campesino, especialmente de su comportamiento y actitud ante la vida. Se trata de una serie de relaciones comparativas con el insecto conocido como "chicharra". 
La comparación es una figura del lenguaje que mediante una conexión lógica y gramatical articula elementos en términos de semejanza y no de simple ejemplo o yuxtaposición. Constituye un modo de desdoblamiento del sentido y una forma práctica del intelecto orientada hacia una función cognoscente. Aporta, además, una plasticidad a los enunciados. La comparación fortalece el proceso de comunicación porque apunta hacia la claridad y la concreción, con lo cual marca una notable diferencia en relación con los discursos especulativos $^{1}$. Es imprescindible la existencia de dos términos, donde ninguno de ellos experimenta una mutación del significado.

En cuanto al término "chicharra", la Real Academia Española de la Lengua informa en la acepción número 1 que es una voz que proviene de cigarra y está influida por la onomatopeya “chich". La define como "insecto hemíptero, del suborden de los homópteros, de unos cuatro centímetros de largo, de color comúnmente verdoso amarillo, con cabeza gruesa, ojos salientes, antenas pequeñas, cuatro alas membranosas y abdomen cónico, en cuya base tienen los machos un aparato con el cual producen un ruido estridente y monótono. Después de adultos solo viven un verano" (DRAE, 1992: 474)².

En Costa Rica, la chicharra es un insecto que mide entre 10 y 50 milímetros. Se caracteriza, además, por ser verdosa, grisácea, negra o café, y por presentar áreas brillantes u opacas. Se distingue también por la presencia de tres ocelos, ojos bulbosos y órganos productores de sonido en los machos. Tiene alas transparentes que miden el doble de su cuerpo y a diferencia de otros insectos homóptera, no salta; se esconde o se ubica en las partes altas de los árboles y entre el follage, y produce un sonido muy audible para el ser humano. La chicharra macho puede cantar de manera sincronizada o individualmente y su canto ha sido asociado con el cortejo. Predomina el canto de la chicharra en días soleados pero también puede darse en días nublados o con ligeras lluvias.

De acuerdo con Step, es posible interpretar y vivir los sonidos de la cigarra de distinto modo: "Unos han considerado estos sonidos gratos al oído, otros como ruido molesto, y es probable continúen siendo apreciados diversamente, según el temperamento o el estado de ánimo del oyente" (1960:509). En el caso específico del texto que nos ocupa, no se parte de una nota eufónica sino que más bien su canto afecta al oído humano:

\footnotetext{
El sonido chillón, agudo, monocorde, pagando con su vida el delito de cantar. Cantan histéricas, enfermas, hasta que revientan de necias, de tontas, de cantarinas... Que una estalla dilatada hasta el imposible en su obsesión musical, hay miríadas, montones de chicharras que ahogan su quejido de agonía y que cantarán hasta que revienten a su vez agotadas cumpliendo su deber, con rabia, con locura, con delirio. Y mueren, mueren muchas y siempre habrá muchas más que seguirán cantando, incesantemente, constantemente, sin parar (152-3).
}

Siguiendo lo señalado por Step, en el relato el estado de ánimo del sujeto de la enunciación es negativo o pesimista, ya que la voz narrativa se siente profundamente afectada por el sonido de las chicharras. Estos son el insecto con el que compara al campesino, el cual aparece aquí degradado. "Es tan negativa la caracterización de las chicharras que éstas, comparativamente con otros animales, también descritos como detestables, encierran mayores rasgos negativos: Hay muchas otras voces cuando empieza la noche, los grillos, los sapos, las ranas; pero ninguna es así insistente, así poderosa, así resonante y estúpida como la voz de las chicharras que se matan de cantar" (154). Una vez que el texto expone este cuadro sobre las chicharras emerge la comparación con el campesino: "Unido a ese grito agudo y estúpido, hostigado por él, nace el campesino como las chicharras. [...] Ese hombre que nació como esas 
chicharras es el domingo una chicharra a quien no se deja cantar" (154). Con estas formas de comparar al campesino se enfatizan rasgos característicos en equivalencia: la estupidez y la existencia carente de emociones, sentidos y proyectos.

"Campesinos" y "chicharras" nacen para morir sin que ello implique conmover a nadie, porque ambos presentan una vida monótona y aburrida ${ }^{3}$. Las labores que realizan, el canto y el trabajo carecen de motivación y sentido: "Porque así como ella canta, él tiene que seguir abriendo hoyos en la tierra, haciendo hijos en los vientres de sus madres, ensartando sesteos en las ruedas de sus carretas" (154). Esta vida carente de voluntad acerca al campesino al animal porque actúa sin el afán de alegría y sin objetivos, sin razón, la cual distingue al ser humano: "Sin razonamientos y también sin alegría, simplemente porque sî" (155). Además de esa falta de sentido planificado, Oreamuno parece denunciar la terquedad del campesino costarricense, quien se enfrasca en una sola dirección o hecho y no cambia hasta la muerte. Este significante se le adiciona al anterior y genera una imagen negativa en la que el sentido metafórico y comparativo acentúa la relación hombre/animal, en la que el ser humano se encuentra disminuido y rebajado.

Esta imagen se diferencia notablemente de otras como por ejemplo la de Fernando Luján, quien en el poema "Campesinos" de Tierra marinera exalta la figura del campesino con un sentido eufórico y primaveral, optimista por el trabajo y la capacidad de sembrar y dar vida:

Campesinos son, boyeros/ que están arando los campos,

y luego vendrá el invierno/ para regar los sembrados.

Cuando terminen de arar,/ se verán todas las tierras

semejantes a una mar/ de onduladas olas negras.

Campesinos son, boyeros,/ marineros en su mar (1967:77).

\section{Conclusión}

"El espíritu de mi tierra" constituye una reflexión en torno a la circunstancia del ser nacional y a la valoración del campesino, abordándolo con una fuerte emoción y con un amplio espectro de ambigüedad, en el que se resaltan elementos positivos y otros que la autora rechaza. En este último caso lo realiza asumiendo un juego irónico satírico, rasgo que ha caracterizado toda su obra. Al campesino finalmente no se le condena por sus acciones que muchas veces parecen engañosas y falsas, sino por carecer de metas y proyectos definidos, con lo que el texto adquiere una connotación suprema que abriga al país entero y remite a su conocido ensayo "El ambiente tico y los mitos tropicales".

La comparación implica también un gesto de alteridad muy crítico en el que el otro se convierte en un animal, con lo que a nivel genotextual, el campesino es rebajado en un plano ideológico. De esta manera podemos afirmar que la comparación, además de constituir un recurso crítico que aporta a la semiosis textual, se convierte en un modo de construcción del sociograma del campesino en la literatura costarricense y presenta unas formas enunciativas muy particulares y diferentes a las ya señaladas por autores como Manuel González Zeledón, Joaquín García Monge, Max Jiménez, Carlos Luis Fallas, entre otros. Marc Angenot y Régine Robin señalan que 
de vez en cuando el escritor menos hostil al grupo que describe y al que le da la palabra, comete una especie de lapsus, repite pasivamente un fragmento dóxico que el desarrollo mismo de su texto habría debido disolver, deja elementos durmientes, residuos de clichés no atacados (1991:68).

Más allá de esta posición teórica y trascendiendo los condicionamientos ideológicos que podrían detectarse en los textos de los autores citados, Oreamuno asume una posición más drástica y reveladora en la que el campesino ya no es asumido como un elemento decorativo del paisaje y del ambiente, ni como símbolo de nuestra identidad, sino como una distorsión, un ruido o, si se quiere, una fractura del imaginario colectivo nacional.

Esta forma de comparación resulta radical y en alguna medida se explica por la actitud de distancia que en el texto asume la voz narrativa que expone, la cual mira con un gesto de superioridad. Asunto que podría extrapolarse a la autora, pues según José Marín Cañas ella parecía estar "inmóvil sobre un punto cimero" (1961: 364), punto desde el cual asumió un discurso crítico sobre la nacionalidad y el astigmatismo costarricense. Frente a la doxa de Costa Rica, país de avanzada, Oreamuno se impone y descubre la superficialidad que lo caracteriza, proponiendo, como en este texto analizado, la ineludible necesidad de la libertad del pensamiento y del espíritu, para una comprensión amplia y una transformación del ser costarricense. Más allá de una visión esquemática, su aporte se dirige a la exploración de nuevas formas de indagar sobre el país y por lo tanto, de conformar otras visiones necesarias en el pensamiento costarricense.

\section{Notas}

1. En el caso de la comparación literaria, este hecho no implica reducir los enunciados a una función denotativa.

2. La cigarra es símbolo de inmortalidad, y de acuerdo con Tresidder (1999: 58) este simbolismo se justifica en su apariencia disecada y en su larga duración. En Grecia la cigarra era sagrada para el dios Apolo y se relaciona con el mito de Titonio, un mortal amado por Eos (alba). Es, además, considerada como un insecto músico, ya que anatómicamente posee "una cavidad especial en el cuerpo dividida en cámaras por diversas películas, y un tambor o timbal especialmente delicado que el insecto hace vibrar para producir el sonido inicial"' (Step, 1960:510).

3. Carlos Salazar Herrera en su cuento "El temporal", también presenta una concepción negativa de la chicharra: "Había entrado el temporal con necedad de chicharra" (1963:130).

\section{Bibliografía}

Angenot, Marc y Régine Robin. 1991. "La inscripción del discurso social en el texto literario". Sociocríticas: Prácticas textuales. Cultura de fronteras. Pierrete Malcuzynski (ed.). Amsterdam-Atlanta: Rodopi, 51-79.

Aristóteles. 1963. Poética. Buenos Aires: Emecé Editores.

Luján, Fernando. 1967. Tierra marinera. San José, Costa Rica: Editorial Costa Rica. 
Oreamuno, Yolanda. 1961. A lo largo del corto camino. San José, Costa Rica: Editorial Costa Rica.

Quesada Soto, Álvaro. 1986. La formación de la narrativa nacional costarricense. San José, Costa Rica: Editorial de la Universidad de Costa Rica.

Real Academia Española de la Lengua. 1992. Diccionario de la lengua española. $21^{\text {a }}$ ed. Madrid: Espasa Calpe.

Ross, Herbert. 1973. Introducción a la entomología general y aplicada. Barcelona: Ediciones Omega.

Salazar Herrera, Carlos. 1963. Cuentos de angustias y paisajes. San José, Costa Rica: Editorial Costa Rica.

Soto de Ávila, Víctor. 1961. "Yolanda Oreamuno". Yolanda Oreamuno. A lo largo del corto camino. San José, Costa Rica: Editorial Costa Rica: 317-20.

Step, Edward. 1960. Maravilla de la vida de los insectos. Madrid: Espasa Calpe.

Tresidder, Jack. 1999. Diccionario de los símbolos. México: Grupo Editorial Tomo. 